\title{
SOME CONSIDERATIONS ON EMOTIONAL INTELLIGENCE
}

\author{
*Selim Aren \\ *Sibel Dinc Aydemir \\ *Gebze Institute of Technology, Turkey
}

\begin{abstract}
As being a well-supported and strong variable, emotional intelligence can predict the dependent variable especially in the domains which focused on the individuals. Mostly, researchers are more likely to confront emotional intelligence construct if they are aiming to investigate behavior. Because emotional intelligence could help the researchers in explaining why an individual (e.g. employee, manager, leader, investor, student) behaves in that way. Yet, great care for this variable should have been exerted by researchers. Accordingly, this paper aims to manifest some important considerations on emotional intelligence as both a construct and a measurement scale for researchers who intend to study on it. In this context, some emotional intelligence studies will be reviewed in the light of these considerations. Therefore, this paper proposes that researchers should include personality traits or cognitive intelligence together with emotional intelligence into their research models in order to question its possible relation to personality and its incremental validity above personality and/or cognitive ones. While studying on emotional intelligence, it is also advisable to select a more obvious criterion variable for the sake of plausible logical connections between variables. Additionally, when studying on any phenomenon as well as emotional intelligence, it should be remembered that cross sectional data do not warrant nexus of causality. Rather, longitudinal data enabling these kind of attributions should be used.
\end{abstract}

KEYWORDS: Emotional intelligence, ability model, personality.

\section{INTRODUCTION}

However enounced before, for more than twenty years, scholars have devoted substantially much effort toward investigating emotional intelligence in diverse settings. This intensively emphasis can be rationalized on the grounds that emotions play a crucial role on the way why people behave. In this context, emotional intelligence has been carried on any settings (strategic management, decision making, academic or social success, taking risks- financial, health, or social) in which individual differences could make a divergency.

Although a useful construct explaining individual differences, researchers are advised to be careful while studying on it. Several scholars have theoretically and empirically manifested some precious considerations or concerns. From theoretical view, establishing proper logical connections, scrupulously selecting criterion variable and designing a longitudinal study instead of cross sectional are crucial. Empirically, questing emotional intelligence's relation to personality traits or cognitive intelligence and identifying its incremental value above personality and/or cognitive intelligence have significant importance.

Since there exists a variety of emotional intelligence definitions, models, and instruments, this paper is expected to contribute future studies by manifesting some fundamental topics on emotional intelligence and by communicating academic conversation regarding deficiencies and concerns. On the other hand, it may be exaggerated to proclaim that every issue about this concept could be found in this prone study. This study simply gives some cues while researchers concentrating on emotional intelligence.

In this regard, this paper firstly will give definitive issues on emotional intelligence. Then, some criticism directed toward this construct will be introduced and subsequently emotional intelligence studies will be reviewed in the light of these criticisms. Lastly, an overview and some suggestions will be presented for researchers.

\section{Emotional Intelligence}

Emotions are seen as coordinated reactions, ensuing various psycological integral parts (i.e., cognitive, motivational, physiological, experiential systems) and these reactions are seen internally or externally while 
carrying positive or negative meanings (Salovey and Mayer, 1990). Since both concepts are sometimes misused, it could be stated that mood is different from emotions in some aspects which it is free standing and not attributed to any object and lasting for some time period (Olson, 2006). On the other hand, intelligence represents a broad set of abilities which are connate and settled (Humphrey et al., 2007). That being the case, how can emotion and intelligence, the seemingly different concepts, come together? Because emotional intelligence is a construct which aims to measure a set of emotional abilities. Proponents of this construct (i.e. Peter Salovey and John D. Mayer) view it as a subset of social intelligence.

Social intelligence was first coined by father Thorndike (1920) in order to define competencies which employed for apprehending and handling people. Social intelligence is one of three forms of intelligenceabstract, mechanical, social (Landy, 2005). It is cited from Hess and Bacigalupo (2011) that emotional intelligence is first used in a doctoral thesis by Payne (1983).

Salovey and Mayer (1990) defined this construct as 'the ability to monitor one's own and others' feelings and emotions, to discriminate among them and to use this information to guide one's thinking and actions'. This definition is given here because it is deemed as the narrower one compared to other emotional intelligence definitions which encompass many life dimensions since emotional intelligence includes emotional dimension of life (Badenhorst and Smith, 2007).

By the way, the definitions of emotional intelligence are discriminated by the way scholars approach toward the concept. These approaches can be divided into two main model classes (i.e. ability model and mixed model). Some scholars differentiate them according to whether they are cognitive, non-cognitive, competency based or not. Hence, ability model (Mayer and Salovey, 1990) shows similarities with cognitive intelligence whereas models of competency based (Goleman, 1995) and non-cognitive (Bar-On, 1997) constitute mixed models (Rosete and Ciarrochi, 2005).According to some scholars, its definitions can be categorized whether they are narrow or broad. In this regard, while Salovey and Mayer's definition (1990) can be thought as narrow, Bar-on (1997) and Goleman's definitions (1995) as broad (Badenhorst and Smith (2007). Therefore, wide range of EQ measurements can be stemmed from these different approaches. In his review, Conte (2005) critiqued some primary measures (i.e., Emotional Quotient Inventory, Mayer-SaloveyCaruso Emotional Intelligence Test, Multifactor Emotional Intelligence, Emotional Competence Inventory). Owing to considerable divergency of these definitions, Badenhorst and Smith (2007) touched upon the necessity of a prevailing or shared speech regarding emotional intelligence in order to make the concept clear.

After communicating some in terms of definitive issues, it could be mentioned about that emotional intelligence has been enormously studied in the literature from the viewpoints of various domains. Accordingly, emotional intelligence indicated important effects on these diversing settings: (1) strategic management (Voola, Carlson and West, 2004; Leban and Zulauf, 2004; Polychroniou, 2009), (2) decision making (Bell, 2011; Hess and Bacigalupo, 2011; Kidwell et al., 2008, (3) leadership (Batool, 2013; Rosete and Ciarrochi, 2005; Dulewicz and Higgs, 2003), (4) risk management (Hillson and Murray-Webster, 2006), (5) learning (Joshi, 2013), (6) financial and economic (Dohmen et al., 2010; Ameriks et al., 2009), (7) entrepreneurship (Kamalian et al., 2011; Foo, 2011), (8) education (Gunduz, 2013; Humphrey et al., 2007), (9) risk taking (Yip and Cote, 2012; Sjöberg and Engelberg, 2012; Trinidad et al., 2004), (10) work performance (Jorfi et al., 2010), (11) school adaption (Erasmus, 2007) and (12) organizational change (Vakola et al., 2003).

Especially in leadership, how important emotional intelligence is can be understood by the quotation from well-regarded organizational psychologist, Warren Bennis (1989):

In those fields I have studied, emotional intelligence is much more powerful than IQ in determining who emerges a as leader.

Emotional intelligence has great importance not only for emergence of a leader but also for acquisition of competitive advantage through leadership capability (Voola, Carlson, and West, 2004). While authors proposing this connection, they tapped into key tenets of resource-based view implying firm specific capabilities make difference in firm profitability. And emotional intelligence can influence leadership capability which has three dimensions (i.e., cognitive, emotional and behavioral dimensions). Additionally, product development as a precious instrument in gaining competitive advantage leaded project management 
to be highly appreciated by firms. Some research concluded that emotional intelligence made a contribution to project performance by having impact on the project manager's transformational leadership style (Leban and Zulauf, 2004). In another study, by enhancing team effectiveness with subordinate, emotional intelligence dimensions are found to relate positively to transformational leadership (Polychroniou, 2009).

In particular domains, it is proved that emotional skills have important effects on performance outcomes. In consumer domain, Kidwell, Hardesty and Childers (2008) found that consumer performance was more explained by emotional abilites beyond cognitive ones. Hess and Bacigalupo (2011) concluded that both the outcomes and the processes would be enhanced if emotional abilities are applied practically to the decision making setting. In a study of focusing on entrepreneurial opportunity evaluation, Foo (2011) manifested that special attention has been devoted to cognitive processes of the entrepreneurs and that there existed little research on how emotions could influence entrepreneurs evaluating business opportunities.

In decision making context, emotion and rationality could have been viewed by many people, especially by the rationalists, as oxymoron but the concept of emotional intelligence accommodates these two contradictory terms. Contrary to rationalists, recent decision making researchers have considerably shifted their concentrations on applying emotional intelligence abilities and behaviors on decision making processes on the grounds that it would enhance both the output and all the processes in decision making problems (Hess and Bacigalupo, 2011). The reason of this enhancement could be expressed in four fundamental points as quoted from Humphrey et al. (2007):

- Emotions are neutral. They contain information which needs to be recognized and understood in order to inform decision-making (Damasio, 1994).

- Emotion can be seen as being central to individuals' ability to establish which problems they should solve and in which order they should address them (McPhail, 2004.

- Emotion helps individuals to identify the elements that reason must take into account when a decision is being made (De Sousa, 1990).

- Emotion can be seen as establishing appropriate goals towards which reason can work.

Given emotions as integral part of rational processes, when individuals could improve their emotional intelligence, their decision-making would progress well (Humphrey et al., 2007).

In the course of life, people make decisions under uncertainty conditions. And the nature of the uncertainty could not allow rational processes to be functioning correctly. Because what would happens is estimated not calculated. Hence, the lack of controlling uncertain conditions causes anxiety in people. At this point, it is said that emotional intelligence facilitates the well handling of anxiety as a negative affect. On the other hand, anxiety or any negative affect is viewed as an impediment that could cause poor decision making thereby causing peoples' efforts to divide between making a choice and managing their moods skilfully (Chapman, 2006). Additionally, it is addressed that being able to recognise and apprehend our emotions would influence choice behavior by reducing avoidable mistakes.

Under any uncertain conditions, risk taking is sometimes indispensible for decision makers. Therefore, researchers have devoted considerable efforts toward examining emotional intelligence's role on any risk taking behavior. Joshi (2013) provided evidence that students with high emotional intelligence are more likely to take risks in learning environment. Ameriks et al. (2009) concluded that investors tending to display good investment performance are those with high level of emotional intelligence. Albeit following a different methodology (i.e. content analysis), Satterfield (1998) stated that cognitive and affective states affected risk taking. Kamalian et al. (2011) found that the dimensions of emotional intelligence have influenced risk taking dimension of entrepreneurial orientation. According to Foo, (2011) emotions played significant role on entrepreneurial opportunity evaluation via risk perception. More clearly, fear as a negative emotion causes high risk perception while happiness leads to low risk perception. Yip and Cote (2012) have drawn conclusion that understanding emotion dimension diminishes incidental anxiety while taking risks. Compared to non students in finance, Sjöberg and Engelberg (2009) concluded that students specializing in finance are more likely to take high economic risk and to have high emotional intelligence scores. 
Some researchers have placed intensively emphasis on this construct and provided evidence on its effects. Goleman (2005) proposed that school success can be, equally or more, predicted by emotional intelligence than intellectual intelligence. Rosete and Ciarrochi (2005) revealed that emotional intelligence explained variance which was not explained by intellectual intelligence or personality (i.e. big five). Lopes et al. (2003) detected significant modest relations between emotional intelligence and personality and verbal intelligence. But they found that even big five and verbal intelligence controlled, EQ strongly explained the dependent variable (i.e., satisfaction with social relations).

\section{Some Critiques on Emotional Intelligence}

This variety of emotional intelligence scales and the intensively emphasis placed on that construct have not escaped from the attention of some scholars. Interestingly, emotional intelligence as both a construct and a measurement has drawn excessively criticism. Firstly, Conte (2005) questioned that EI measurements could evaluate which were already done by other deep- rooted constructs such as big five personality dimensions. It is said that emotional intelligence shows -albeit low or moderate- associations with personality factors and cognitive ability.

In this context, there also have been some precious investigations towards identifying the relation of emotional intelligence to cognitive abilities (such as academic intelligence or intellectual intelligence) and personality traits. To exemplify, Van der Zee et al. (2002) examining the relatedness of emotional intelligence to personality traits and academic intelligence identified low and strong associations for academic intelligence (with explained variance $\% 9$ or less) and personality traits (\% 59 for self and $\% 28$ for other scales) respectively. However, Humphrey et al. (2007) reported that it is not shown the evidence of any relatedness of various emotional intelligence measures to cognitive intelligence (i.e., IQ) but that a weak relationship with verbal IQ is found. In their meta-analytic study, composed of 69 different studies which they pointed out correlations between emotional intelligence and other variables (e.g., big five and general mental ability), Van Rooy and Viswesvaran (2004) indicated that emotional intelligence correlated general mental ability $(0,22)$ and big five personality dimensions $(0,23$ with agreeableness and openness to experience; 0,34 with extraversion).

Another criticism is that researchers, especially proponents of this models, have attached excessively importance on EI. Especially, it is better to ruminate before claiming that emotional intelligence causes to a particular dependent variable such as success or job performance for two main reasons (Landy, 2005). First, the logical connections of this proposed relation is not rather explicit. It is advisable that researchers choose more apparent dependent variable (e.g., leader emergence instead of leader success or job performance). Secondly, claiming causal relationships based on cross sectional studies is not appropriate.

Badenhorst and Smith (2007) juxtaposed major criticisms which may stemmed from the deficiency of a prevailing EQ definition. These criticisms can be gathered under the titles of (1) relatedness of EQ to other deep-rooted constructs (e.g. big five), (2)problematic measures of EI models, (3)malleability of EI versus inalterability of IQ , (4) difficulty of verificating premises about the prominence of EI.

Similar to Conte (2005) but in a different way, Landy (2005) manifested some scientific matters on EQ. Considering the relatedness of EQ to some other constructs (e.g. personality), it is advisable to parsimoniously design our studies In other words, if equal in defining a behavior, two variables must be preferred instead of three variables. As another but most emphasised suggestion, Landy (2005) gave notice that researchers must be more careful while choosing the dependent variable. To exemplify, it is proposed that more apparent dependent variable (i.e., leader emergence) should be preferred to a non-obvious variable (i.e., leader performance). Additionally, it is suggested to incorporate both EI and big five personality measures into the model in order to search for any overlap or redundancy.

Conte (2005) also suggested that future research must be designed to examine the incremental contribution of emotional intelligence on the dependent variable beyond other established estimators (e.g., big five).

\section{Review of Emotional Intelligence Studies}

It has been mentioned in the previous sections that considerably much effort have been exerted by researchers on emotional intelligence. They investigated emotional intelligence as an individual difference 
factor in divergent settings. These studies will be sufficiently reviewed in this section, while considering criticisms mentioned above.

In good part of these studies, it is claimed that emotional intelligence could predict underlying research variable more than cognitive abilities. For instance, Kidwell, Hardesty and Childers (2008) described the Consumer Emotional Intelligence Scale development. After proved this domain specific scale's nomological and discriminat validity, they employed this construct in explaining food choices among 231 undergraduate business students. The study revealed that emotional abilities explained food choices better than cognitive abilities which were seen as major predictors of consumer performance. Bell (2011) viewed current studies which take the emotions into consumer decision making consideration against widely cognitive traditional approaches, by accentuating the important role of emotions.

In a study (Rosete and Ciarrochi, 2005), aiming to explore the associations between emotional abilities, personality, cognitive abilities and leadership effectiveness, there existed no significance relation between emotional intelligence and personality factors. They concluded that EI is a discernable construct. After exploring incremental value of emotional intelligence, they found that EI explained more variance than cognitive ability or personality.

As an another example, Van der Zee et al. (2002) investigated whether emotional intelligence relates to academic intelligence and big five personality factors and has incremental validity above them in estimating both academic and social success. The study conducted through 116 students from various faculties has revealed that big five estimated emotional intelligence more than academic intelligence. More specifically, extraversion is more related to empathy and a combination of big five factors constituted emotional control. As for academic intelligence, it has found to have a modest relation to emotional intelligence. They performed stepwise regression in order to quest the existence of incremental validity and the regression results showed that emotional intelligence has an incremental validity above other two constructs, meaning that it explained considerable part of variance in academic and social success.

A study (Lopes et al., 2003) conducted among 103 students with the aim of searching for any linkages between personality and emotional intelligence pointed out that emotional intelligence related to big five factors and agreeableness had a highest linkage (\% 33) to managing emotions. They stated that MSCEIT (Mayer, Salovey, and Caruso Emotional Intelligence Test) displayed limited overlap with verbal intelligence and personality. More importantly, emotional intelligence has remained the statistically significant predictor of social relationships even after controlling for personality and verbal intelligence (i.e., incremental validity).

The incremental value of emotional intelligence above personality has been sustained in organisational setting. Vakola et al. (2004) inquired the role of emotional intelligence and personality on organizational change process. They proposed that these individual differences may influence the attitudes toward change. In this study whose participants were 137 professionals from publicly and privately owned organizations, hierarchical multiple regression results revealed that openness to experience and agreeableness positively explain attitudes towards change and that use of emotions has more influence than this two personality dimensions in explaining the underlying variable.

A meta- analysis combining other emotional intelligence studies (Van Rooy and Viswesvaran, 2004) demonstrated that emotional intelligence was a worthy performance estimator. However, the study also indicated that this construct has greatly correlated to personality (i.e., big five) factors. Yet, Curci et al. (2013) concluded that MSCEIT as a measure satisfactorily discriminated from big five personality factors and some intelligence measures.

Briefly, these studies demonstrate that emotional intelligence has an incremental value above personality and cognitive intelligence whereas this construct correlated to those deep-rooted ones.

\section{DISCUSSION}

Based upon the valuable research on emotional intelligence, it can be said that this construct has been useful and valuable in explaining any underlying dependent variable. Additionally, considering individual differences' explaining power on any settings in which individuals acts as agents, emotional abilities can predict variance in dependent variable. 
However, trying to attribute many instances to emotional intelligence by forcing logical connections may be erroneous. Hence, it is proposed to be able to careful in selecting dependent variable. More apparent ones have been advisable instead of success, outcome, performance. At the same time, any claim that states emotional intelligence causes to something (e.g., success or performance) depending on cross sectional data has been viewed as inaccurate. Put it differently, cross sectional studies do not warrant causal relationship between variables. Rather, a longitudinal study may enable this kind of causality since it demonstrates a change of selected variables. This metaphor could be suitable to understand; cross sectional data can be seen as a photo at any time which is taken whereas longitudinal data can be viewed as a video which displays the change.

In general, being encountered with studies assessing the incremental validity of emotional intelligence above other deep-rooted constructs (i.e. big five and cognitive intelligence) had not been so surprising after reading some criticisms on having to examine the existence of added value of emotional intelligence. In other words, it seems that emotional intelligence researchers have taken these critiques into account. Or, for researchers, it is better to take personality and/or cognitive intelligence when deciding on studying emotional intelligence in order to see its incremental value above other two. Remembering the relationship between emotional intelligence and personality or cognitive intelligence, the problem of multicollinearity between predictor variables should be considered while designing a research model.

On the other hand, the divergency of emotional intelligence measurements may constitute an impediment for researchers to replicate any validated study. While comparing emotional intelligence studies, any researcher can have some difficulty.

Briefly, although a useful, valuable and pleasant construct to examine on, all prons and cons of emotional intelligence should be considered while making a research including it. 


\section{REFERENCES}

Ameriks, J., Wranik, T., Salovey, P. (2009), ‘Emotional Intelligence and Investor Behavior', CFA Digest, August 2009, pp. 100-104.

Badenhorst, A., Smith, D. (2007), 'Misconceptions About Emotional Intelligence: Deploying Emotional Intelligence in One's Life Dimensions', Journal of Human Resource Management, 5 (3): 1-10.

Bar-On R. (1997), 'Emotional Quotient Inventory: User’s Manual, Multi-Helath Systems, New York, NY.

Batool, B. F. (2013), 'Emotional Intelligence and Effective Leadership', Journal of Business Studies Quarterly, 4(3): 84-94.

Bell, H.A. (2011), 'A Contemporrary Framework for Emotions in Consumer Decision-Making: Moving Beyond Traditional Models', International Journal of Business and Social Science, 2 (17):12-16.

Bennis, W. (1989), 'On Becoming A Leader', London: Hutchinson.

Chapman, J. (2006), 'Anxiety and Defective Decision Making: An Elaboration of The Groupthink Model', Management Decision, 44 (10): 1391-1404.

Conte, J. M. (2005), ‘A Review and Critique of Emotional Intelligence Measures', Journal of Organizational Behavior, 26: 433-440.

Curci, A., Lanciano, T., Soleti, E., Zammuner, V.L. \& Salovey, P. (2013), 'Construct Validity of The Italian Version of The Mayer-Salovey-Caruso Emotional Intelligence Test (MSCEIT) V2.0' Journal of Personality Assessment, 95(5): 486-494.

Dohmen, T., Falk, A., Huffman, D., Sunde, U. (2010), 'Are Risk Aversion and Impatience Related to Cognitive Ability?’, American Economic Review, pp. 1238-1260, DOI: 10. 1257/aer.100.3. 1238.

Dulewicz, V., Higgs, M. (2003), 'Leadership At The Top: The Need for Emotional Intelligence in Organizations', International Journal of Organizational Analysis, 11(3): 193-210.

Erasmus, J.P. (2007), 'The Role of Emotional Intelligence in The Adaptation of Adolescent Boys in a Private School', Published Master Thesis, University of South Africa.

Foo, M. (2011), 'Emotions and Entreprenurial Opportunity Evaluation', Entrepreneurship Theory and Practice', 35 (2): 375-393, DOI: 10.1111/j.1540-6520.2009.00357.x.

Goleman, D. (1995), 'Emotional Intelligence: Why It Can Mastter More Than IQ, Bloomsbury Publishing, London.

Gunduz, B. (2013), 'Emotional Intelligence, Cognitive Flexibility, and Psychological Symptoms in PreService Teachers', Educational Research and Reviews, 8(13): 1048-1056.

Hess, J.D., Bacigalupo, A.C. (2011), ' Enhancing Decisions and Decision-Making Processes Through The Application of Emotional Intelligence Skills', Management Decision, 49(5): 710-721.

Hillson, D., Murray-Webster, R. (2006), 'Managing Risk Attitude Using Emotional Literacy', 2006 PMI Global Congress EMEA Proceedings-Madrid, Spain.

Humphrey, N., Curran, A., Morris, E., Farrell, P., Woods, K. (2007), ‘ Emotional Intelligence and Education: A Critical Review', Educational Psychology, 27(2): 235-254.

Jorfi, H., Jorfi, S., Moghadam, S.K. (2010), 'Impact of Emotional Intelligence on Performance of Employess', Postmodern Openings, Year 1, 4:. 63-74.

Joshi, S.R. (2013), 'A Study of Risk Taking Behaviour of Adolescent Students in Relation to Emotional Intelligence', International Journal for Research in Education, 2(5): 33-36.

Kamalian, A., Yaghoubi, N., Poori, M. (2011), 'Emotional Intelligence and Corporate Entrepreneurship: An Empirical Study', Journal of Basic and Applied Scientific Research, 1(6): 471-478. 
Kidwell, B., Hardesty, D.M., Childers, T.L. (2008), 'Consumer Emotional Intelligence: Conceptualization, Measurement, and The Prediction of Consumer Decision Making', Journal of Consumer Research, 35(1), DOI: $10.1086 / 524417$.

Landy, F.J. (2005), 'Some Historical and Scientific Issues Related to Research on Emotional Intelligence', Journal of Organizational Behavior, 26: 411-424.

Leban, W., Zulauf, C. (2004), 'Linking Emotional Intelligence Abilities and Transformational Leadership Styles', The Ledarship \& Organization Development Journal, 25(7): 554-564.

Lopes, P. N., Salovey, P., Straus, R. (2003), 'Emotional Intelligence, Personality, and The Perceived Quality of Social Relationships', Personality and Individual Differences, 35: 641-658.

Olson, K. R. (2006), ‘A Literature Review of Social Mood’, Journal of Behavioral Finance, 7(4):193-203.

Polychroniou, P.V. (2009), 'Relationship Between Emotional Intelligence And Transformational Leadership of Supervisors: The Impact On Team Effectiveness', Team Performance Management, 15 (7/8): 343-356.

Rosete, D., Ciarrochi, J. (2005), 'Emotional Intelligence and Its Relationship to Workplace Performance Outcomes of Leadership Effectiveness', Leadership \& Organization Development Journal, 26(5): 388-399.

Salovey, P., Mayer, J. D. (1990), ‘Emotional Intelligence’, Imagination, Cognition and Personality, 9: 185211.

Satterfield, J. M. (1998), 'Cognitive-Affective States Predict Military and Political Aggression and Risk Taking', The Journal of Conflict Resolution, 42(6): 667-690.

Sjöberg, L., Engelberg, E. (2009), 'Attitudes to Economic Risk Taking, Sensation Seeking and Values of Business Students Specializing in Finance', Journal of Behavioral Finance, 10(1): 33-43.

Trinidad, D. R., Unger, J.B., Chou, C., Azen, S.P., and Anderson, J. (2004), 'Emotional Intelligence and Smoking Risk Factors in Adolescents: Interactions on Smoking Intentions', Journal of Adolescent Health, 34 (1): 46-55.

Vakola, M., Tsaousis, I., Nikolaou, I. (2004), 'The Role of Emotional Intelligence and Personality Variables on Attitudes Toward Organisational Change', Journal of Managerial Psychology, 19 (2): 88-110.

Van Der Zee, K., Thijs, M., Schakel, L. (2002), 'The Relationship of Emotional Intelligence with Academic Intelligence and The Big Five', European Journal of Personality, 16:103-125.

Van Rooy, D. L., Viswesvaran, C. (2004), 'Emotional intelligence: A Meta-Analytic Investigation of Predictive Validity and Nomological Net', Journal of Vocational Behavior, 65: 71-95.

Voola, R., Carlson, J., West, A. (2004), 'Emotional Intelligence and Competitive Advantage: Examining The Relationship From A Resource-Based View', Strategic Change, 13(2): 83-93.

Yip, J. A., Cote, S. (2012), 'The Emotionally Intelligent Decision Maker: Emotion- Understanding Ability Reduces The Effect of Incidential Anxiety on Risk Taking', Psychological Science, DOI: 10. $1177 / 0956797612450031$. 